\title{
Smart Cloud Education-The First Online International Chinese Education Promotion Project in Africa
}

\author{
Qirui Yan, Zhuoer Shi \\ Zhejiang Normal University, Jinhua, China \\ Email: 707231203@qq.com
}

How to cite this paper: Yan, Q.R. and Shi, Z.E. (2022) Smart Cloud Education-The First Online International Chinese Education Promotion Project in Africa. Open Access Library Journal, 9: e8495.

https://doi.org/10.4236/oalib.1108495

Received: February 16, 2022

Accepted: March 6, 2022

Published: March 9, 2022

Copyright () 2022 by author(s) and Open Access Library Inc.

This work is licensed under the Creative Commons Attribution International License (CC BY 4.0).

http://creativecommons.org/licenses/by/4.0/

\section{Open Access}

\begin{abstract}
In the context of the normalization of the epidemic, it is of great practical significance to innovate the promotion of Chinese language and culture based on the policy of helping to build a "community with a shared future for mankind" and promoting the construction of the "Belt and Road" initiative. Therefore, based on the accumulation of previous practice, relying on the brand advantages of Confucius Institute and Zhejiang Wisdom Cloud online support teaching platform, this study forms an innovative mode of remote online Chinese teaching, breaks the time and space constraints, and realizes the real implementation of "Internet + education". At present, Zhejiang Smart Cloud Public Service Center has been registered and established. It cooperates with 14 organizations such as Tencent Charity to form a high-quality teaching resource base, provide a professional and standardized Chinese learning platform for more than 5000 international students, and drive more than 1200 normal university students to participate in volunteer service. It is committed to realizing professional online Chinese teaching and promoting the international promotion of Chinese culture.
\end{abstract}

\section{Subject Areas}

E-Learning and Knowledge Management

\section{Keywords}

Online Education, Chinese Language Teaching, A Community with a Shared Future for Mankind, The Belt and Road

\section{Introduction}

As the first "Confucius Institute in the Air" along the Belt and Road, the project 
responds to the call of the National "Community with a shared future for mankind". Under the global situation of fighting against the epidemic, relying on the support teaching platform, the project builds online Chinese series courses, holds Chinese cultural exchange activities, and commits itself to professional teaching and large-scale promotion of Chinese. The project provides a professional and standardized Chinese learning platform for international Chinese language lovers [1], enabling more Chinese language lovers to experience professional Chinese teaching without going abroad and improve their Chinese application level.

\section{Project Content}

Based on the "Internet + education" system, the smart Cloud public welfare team strives to develop education informatization and innovate and practice the remote online teaching mode. This project recruits volunteers from normal colleges and universities to set up characteristic Chinese courses and online cultural exchange activities to promote the realization of a new model of high-quality and self-producing online education.

\subsection{Open Online Chinese Courses}

Based on the teaching mode of remote online and live interactive classes, a three-dimensional cross-selective regional curriculum system is constructed: Chinese is the main language, supplemented by online communication activities. The new teaching evaluation system of "teaching by learning" is adopted to ensure the systematization and scientization of the whole teaching system.

\subsection{Online Promotion of Chinese Culture}

Organize online interest classes of Chinese culture, carry out interest training with a certain traditional Chinese culture as the theme, such as Interest classes of Chinese characters and calligraphy, folk art appreciation classes, etc., organize Chinese culture propaganda activities in Africa, and promote Chinese culture by means of new media.

\subsection{Conducting Online Cultural Exchange Activities}

"Smart Cloud Exchange" brand activities focus on smart education, college students at home and abroad discuss hot topics; the regular activities of "Chinese Cloud Sharing" focus on Chinese communication, and use the learned Chinese to exchange experience. Exercise Chinese application ability regularly, and strengthen the interaction and communication between international teachers and students.

\subsection{Inviting Famous Experts to Guide Teaching}

The project invited expert consultants in Zhejiang province to conduct course design and teaching guidance to ensure the quality of the course. In addition, 
college volunteers are selected layer by layer to ensure their teaching level.

\section{Project Practice}

Through the cooperation with Confucius Institute, the project has established an online education practice base, which has attracted more than 1000 international Chinese language lovers from more than 10 countries such as Egypt, Italy and Pakistan to take online Chinese courses. At present, Zhejiang Smart Cloud Public Service Center has been registered and established. In long-term cooperation with 14 organizations such as Tencent Public Service, more than 1200 students of Zhejiang Normal University and Beijing Normal University have been encouraged to participate in volunteer service. The team was selected as the Outstanding Volunteer poverty Alleviation case of The State Council Poverty Alleviation Office, won the national Public Welfare Communication "Excellent Project", Zhejiang Province "the most Beautiful Love Story" and other national provincial awards and honors, and received the attention of more than 100 media reports such as Xinhua News Agency, China Education Daily front page. Relying on the resources of the Alma Mater, the University has set up a special African Research Institute, which has more than 5000 international students, 155 training experts, 43 leading professors, and more than 100 Chinese teachers. They provide teaching guidance for the project and guarantee the quality of Chinese teaching (Data come from the research results of our team).

\section{Project Innovation}

Based on the national strategy, the team created the first online International Chinese education promotion project of "One Belt and One Road" and the innovative Teaching mode of "Internet+" Chinese education. Long-distance online classes are adopted breaking the limitations of time and space, human and material resources, and realizing the integration of online teaching and learning. Promoting international cultural exchanges and cooperation; The First Confucius Institute was established, and the first online Chinese language education was carried out in the Belt and Road region. With the advantage of its own intelligent cloud platform, it invited expert consultants in Zhejiang province to conduct course design and teaching guidance. Build a high-quality team of teachers; adopt the new teaching evaluation system of "teaching by learning" and improve the evaluation mechanism. The initiative enables Chinese lovers in the Belt and Road region to learn professional and standardized Chinese courses, improves learners' Chinese application ability, and effectively promotes international cultural exchanges and cooperation; the use of new media means, combined with the characteristics of educational technology, enrich the forms of Chinese culture publicity, to achieve the comprehensive promotion of Chinese culture.

\section{Social Value}

The project responds to national major strategies such as "community with a 
shared future for mankind", "Going global" and "improving cultural soft power". Under the situation of the normalization of the epidemic and deepening of education informatization, the intelligent Cloud online support education platform organizes expert consultants and provincial famous teachers to design courses and recruits college students volunteers to teach online. It provides a professional, standardized and innovative Chinese learning platform for international Chinese lovers.

First is to improve the Chinese level of learners and reform the form of Chinese curriculum. The normalization of the epidemic has affected the way international Chinese language lovers learn Chinese, and some Chinese language lovers cannot come to China to study. The Chinese learning platform constructed by the project can realize the interaction between teachers and students in the same time and space relying on online interactive courses. More Chinese lovers can experience professional Chinese teaching without going out, improve their understanding of Chinese language and Chinese culture, and improve their Chinese application level [2]. The platform has provided online teaching for more than 5000 learners, effectively improving their Chinese proficiency. Second, to promote the employment of college students, enhance the ability of college students. The platform recruits a large number of normal college students to participate in online volunteer services, and provides online teaching for Chinese enthusiasts with their knowledge reserves and skills, so as to provide a practical training, work-study and employment platform for normal college students. In the process of practice, it not only helps normal university students to improve their personal education and teaching level, but also promotes the employment of college students. Third, we will help promote Chinese language education and promote international cultural exchanges and dissemination. Project combined with the education technology professional characteristics, relying on the "wisdom" public platform to make and share Chinese culture series micro class, for Chinese learners learn, at the same time rich online propaganda form of Chinese culture, making Chinese culture propaganda site, to WeChat number, BBS and other public as medium, using video, text, images, and other forms of the Chinese culture promotion. At the same time, the two parties participating in the platform can realize effective interaction and dialogue, which is conducive to the exchange and dissemination of different countries' cultures.

\section{Major Contributions}

Based on the technology, resources and service system of "Internet + education", the wisdom Cloud public service team strives to develop education informatization, innovate and practice remote online classes, and build the first online Chinese international education promotion platform in Africa. After the accumulation and implementation of the project, the following contributions have been made:

One is to innovate the Chinese education model, realize the distance online 
teaching across time and space, and improve the Chinese level of learners; The second is to form a high-quality Chinese teaching resource library, relying on the Alma mater of the team and various universities and institutions, making full use of school resources to record teaching videos of famous teachers; Three is to promote the online Chinese international promotion, cooperation with Ukraine, Cameroon, mozambique, Tanzania, United States of Confucius institutes and Confucius classrooms, 3 extensive teaching Chinese and spread Chinese culture, form is given priority to with online Chinese teaching to promote Chinese culture, Chinese and foreign cultural exchanges and regional problems, a new situation of the research go hand in hand.

\section{Development Prospects}

Taking advantage of the accumulation of projects and reputation in the early stage, "Wisdom Cloud" online support education platform will be committed to creating the first online Chinese international education promotion platform in "One Belt and One Road". In terms of base construction, the project will focus on the "Belt and Road" region, and cooperate with schools in ASEAN, West Asia, central and Eastern Europe to promote smart cloud online Chinese international education. At the same time, we will contact the Confucius Institutes and Confucius Classrooms in cooperation with our school to establish the influence of the program in the international education industry. In terms of human resources, we broke the inter-school limitation, recruited more professional volunteers from Beijing Normal University and other universities and social organizations, and invited experts from the School of Teacher Education of Zhejiang Normal University to train local teachers' teaching skills, so as to improve teachers' level in an all-round way. In terms of network quality, China will cooperate with China Mobile and China Unicom to make effective use of 5G technology to ensure the smooth development of online learning platforms. In terms of course content, it pays attention to updating teaching concept, strives to realize personalized teaching, constantly optimizes course teaching content, designs different teaching programs according to different individuals, so that students can choose conditionally and promote students' development and progress to a greater extent [3].

\section{Conclusions and Recommendations}

The normalization of COVID-19 has had a profound impact on international Chinese language education. The epidemic has impacted traditional teaching models, brought a series of new challenges, and triggered new thinking among educators, bringing new opportunities for the transformation and upgrading of international Chinese language education. In the future, the construction of the project will improve the occasion, for those routes, and change, uphold the beginner's mind, the outbreak of actively explore and perfect the normalized under the background of international Chinese teaching promotion path, continuously 
push forward the vigorous development of Chinese international education, contribute more to the dissemination and development of Chinese education, let along all the way "national Chinese lovers everybody can speak" Chinese, Write "Chinese characters"!

\section{Fund Project}

2020 Innovation and Entrepreneurship Training Program for College Students of Zhejiang Normal University (Project No.: 2020R404015).

\section{Conflicts of Interest}

The authors declare no conflicts of interest.

\section{References}

[1] Wang, X. (2018) The Role of Chinese Language Teaching in International Education. Language Teaching and Research, 20, 7.

[2] Chen, J.Y. (2011) Study on the Mode of Running Confucius Institutes in Thailand. Journal of Yunnan Normal University: Teaching Chinese as a Foreign Language, 9, 4.

[3] Munkhbat, U. (2014) Research on Network Neologism Communication from the Perspective of Chinese International Education. Master's Thesis, South China University of Technology, Guangzhou. 